\title{
A Wavelet Coherence Analysis: Contagion in Emerging Countries Stock Markets
}

\author{
Harun Ercan ${ }^{1 *}$, illhami Karahanoğlu² \\ ${ }^{1}$ Finance Department, Faculty of Business Administration, Corvinus University of Budapest, \\ 1093 Budapest, Fővám tér 8., Hungary \\ 2 Faculty of Law, Atılım University, Kızılcaşar Mahallesi, 06830 İncek Gölbaşı, Ankara, Turkey \\ * Corresponding author, e-mail: harunerc@gmail.com
}

Received: 25 September 2017, Accepted: 27 April 2019, Published online: 07 August 2019

\begin{abstract}
This study aims to investigate the financial contagion during and after Greek Crisis to observe the impact on global economy. Financial contagion may affect the portfolio risk management, the formulation of monetary, fiscal policy, strategic asset allocation and pricing. To analyse the contagion after Greek Crisis, the co-movements of six stock exchange markets have been studied for an 8-year term. For this study between countries' time series, bivariate wavelet technique called wavelet coherence is employed, and Matlab 2016a wavelet tool is used for the analysis. Daily closing prices of stock market indices of six countries, Greece (ASE), UK (FTSE100), Germany (DAX), Hungary (BUX), Poland (WIG) and Turkey (BIST100) are used in this analysis between 06 March 2009 and 28 February 2017.

This paper targets to show if there is a certain sign for a co-movement between markets during and after Greek Debt Crisis. Therefore, it eventually sets out the benefits or harm of integration in the financial markets by using Wavelet Method. This study contributes the literature by analyzing the effects of contagion among stock markets by using wavelet method. This analysis has been filling the gap in the literature by employing a new technique to explain leverage effect with financial time series data. As wavelet tool displays the leverage effect by comparing crisis and non-crisis periods, the study supports the idea that convergence is adversely affecting the connected markets. According to the results of the study, the contagion is high especially during crisis within European financial markets. whereas positive improvements have less impact on markets.
\end{abstract}

\section{Keywords}

wavelet coherence, Greek Debt Crisis, financial contagion, contagion

\section{Introduction}

Many European Union member countries have high levels of public debt, and this is unsustainable in the long term. Having the largest public debt and one of the largest budget deficits in the European Union member countries, Greece is at the epicentre of the crisis (Belkin et al., 2011). On 16 October 2009, the Greek Prime Minister George Papandreou in his first parliamentary speech disclosed the country's severe problems and immediately after on 5 November 2009 the Greek government revealed a revised budget deficit of $12.7 \%$ of GDP for 2009, which was the double of the previous estimate. Since then, the sovereign spreads rose sharply for most of the euro area countries, causing the biggest challenge for the European monetary union since its creation (De Santis, 2012). At the beginning of 2010, Greece risked defaulting on its public debt just because the global financial crisis during 2008 and 2009 strained public finances, and following disclosures about falsified statistical data pushed up Greece's borrowing costs.

As illustrated in the Fig. 1, GDP growth dramatically decreases while the inflation slows down. In this graph, annual percentage growth rate of GDP at market prices are based on constant local currency. It shows the effects of recession over the period. Particularly in 2011, GDP grow th has reached as for its lowest. In 2014, finally growth rate return to a very low but at least a positive value.

In financial research field, the relationships between the GDP growth, CPI and Bond Market as well as the stock market was the main subject of scientific analysis. Some researchers have found the direct relation between bond and stock market with GDP growth as well as CPI index (Stock and Watson, 1989; Chordia et al., 2005; Vassalou, 2003), whereas the others are more concentrated on pair 


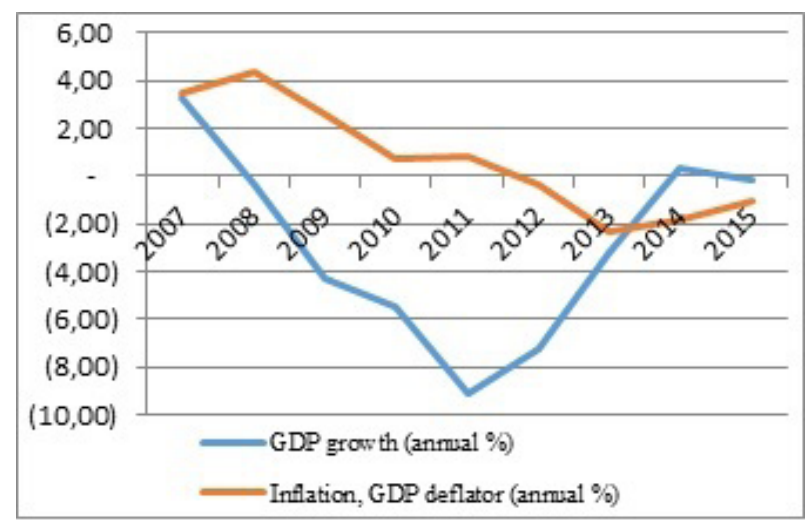

Fig. 1 GDP Growth and Inflation in Greece after 2007 (Source: World Development Indicators (World Bank, n.d.))

relationships between these variables (Banz, 1981; Hull et al., 2004; Beck and Levine, 2004; Huang et al., 2008; Humpe and McMillian, 2009). Moreover, the effect of one countries crisis or bond market as well as the stock market volatilities on another countries macroeconomic variables were another gravitational center of financial scholars (Martin, 1998; Grieco, 1997; Katzenstein, 2005). More specifically, the continent as well as the European trade and political union EU has been suffered from the long standing crisis ongoing in relatively small economies like Greece. As those crises through the European continent have not only economical but also political results through the European continent, such effects should be analyzed scrutinized carefully. Although some researcher gave tried to enlighten the effect of that crisis on EU stock and bond market, they generally used some linear models or some intuitional analysis far from being computational which don't give us the exact or concrete facts (Kentikelenis et al., 2011; Featherstone, 2011; Kouretas and Prodromos, 2010; Beirne and Fratzscher, 2013).
Considering the previous scientific works, it is well seen and understood that GDP growth, CPI stock market and bond markets are interacted very strongly. Besides, it is also shown in previous analysis that there are more and strong economic relationships between some countries, a ground shaking change in one would affect the other one or others directly. Because of that reason, in order to understand Greek crisis effect on EU as well as on the related economies many analysts showed great effort.

By summing all the related analysis and reasoning as well as the deficiencies on those works together, it is realized that such an analysis could be a center of valuable scientific research. The connection between stock markets is increasing continuously. And also the openness of stock exchange markets gets higher. Notably, in emerging countries, demand from international markets aiming portfolio diversification leads growth in the liquidity. However, this integration and co-movement are also causing the failure of portfolio diversification. The crisis started in 2007 and spread to European markets showed us diversification might be low during crises, because of the rise in the interconnection of markets during this period (Baruník and Vácha, 2013).

In the Fig. 2, log scale of closing prices of ASE has been compared with the other stock exchange market closing values. ASE shows a continuous decline after 2008, whereas the other countries markets gained some increase after the hit of Mortgage crisis. The resemblance of FTSE and DAX is not very surprising because of the high correlation between these indexes.

The Athens Stock Exchange general index fell below 500 points in May 2012. The decline slowdown and reached a steady pace after 2012 when Government Bonds spread against US T-bills peaked implying that the risk premium of the country was the highest as shown in Fig. 2.

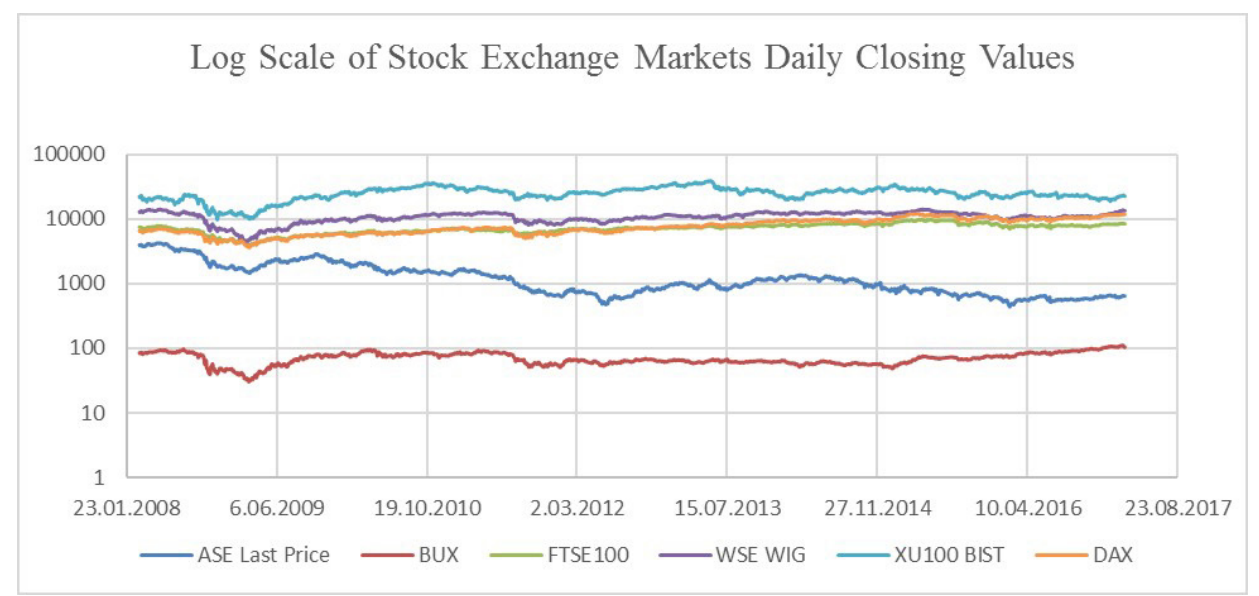

Fig. 2 Log Scale of Stock Exchange Markets Historical Data Display (Source: Bloomberg, n.d.) 


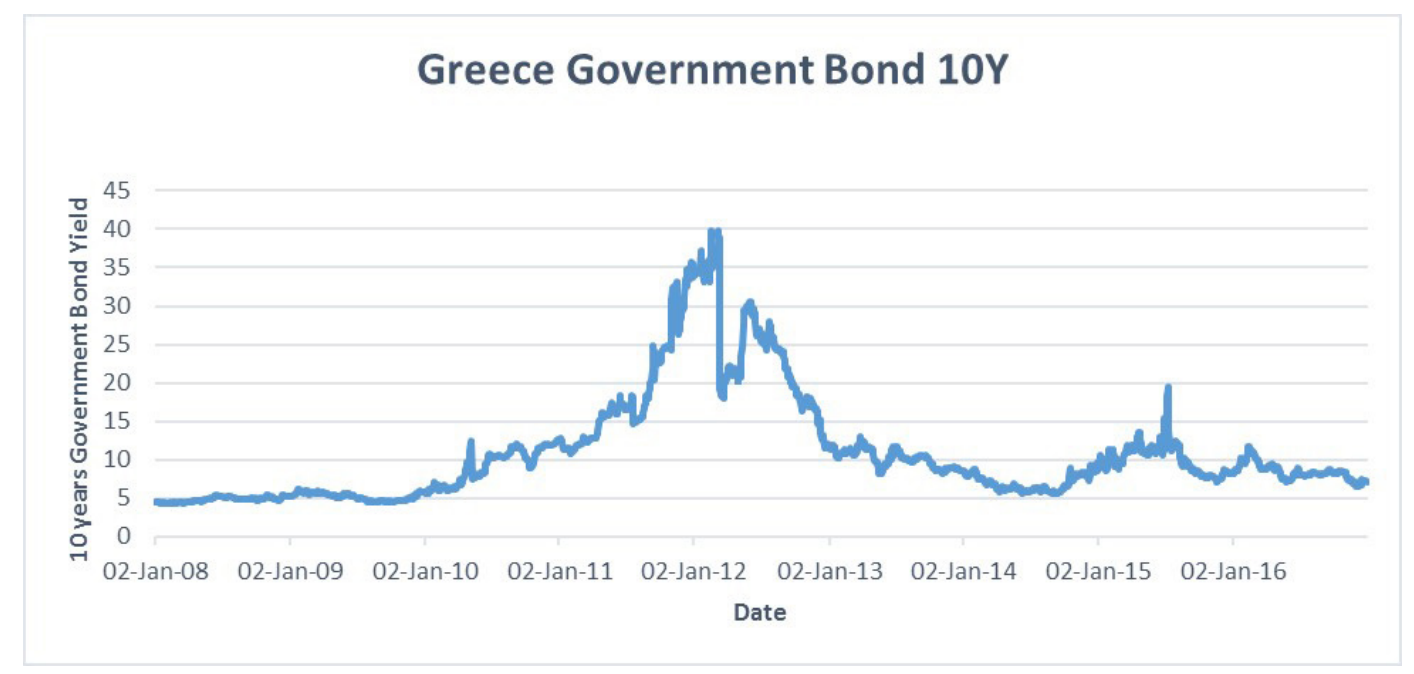

Fig. 3 Greece government bond spread - 10 years' historical data display (Source: Bloomberg, n.d.)

In the last decade, the Greece Government 10-Year Bond Yield has reached an all-time high by 38.967 in Mar 09, 2012 and also recorded a low of 3.21 in June of 2005. Credit default swaps (CDS) enables sellers to take on, or buyers to decrease the default risk on a bond. As the pricing of CDS equals purchasing price of a buyer and demanding price from a seller, protection against the default of an issuer's debt. Therefore, the CDS spreads are displaying the market rates creditworthiness. In the case of increasing risk, the CDS spreads widen.

The primary contribution of this paper to the literature is analyzing the effects of contagion among stock markets by using a different method called as wavelet. This method has been used in different fields as a research technique. However, it has recently been introduced in the finance. The following chapter of this research is explaining the studies in which stock market co-movements are examined. In the third chapter, wavelet methodology is introduced. In the fourth section, data is examined and in the fifth section the results of the study is provided. Last section provides us a comprehensive conclusion of the study with the comparison of the previous research.

\section{Literature review}

Since financial integration became a phenomenon, the research related to the analyze of the market movements have increased enormously. The vast research focused on this area helped the literature to provide a better explanation of the effects of the integration. The results of some studies exhibit that there is a convergence between markets and the coherence among markets can be higher especially when the volatility more spread. However, some studies do not support this idea.

Égert and Kočenda (2007) studied some Eastern and Western Europe stock market co-movements with high-frequency data. Their research includes Czech, Hungarian, Polish, German, French, and UK stock markets and covers the years 2003, 2004 and 2005. Their findings explained that the correlations for daily stock index values are much higher than for high-frequency data.

Connolly et al. (2007) studied the U.S., UK, and German stock and bond markets to illustrate co-movements during high and low volatility periods. Findings of the study illustrate that the coherence is greater when there is low volatility. On the other hand, stock-bond co-movements tend to be positive (negative) following low (high) implied volatility days.

Gilmore et al. (2008) investigated the co-integration in the Central and Eastern European stock markets. Their findings showed that although the co-integration is strong, the signs of convergence to Western Europe are diminishing especially after EU accession.

Candelon et al. (2008) studied investors interests according to the portfolio diversification point of view. They observe that the short-term investors are likely to focus on the co-movement of stock returns at higher frequencies, therefore, on short-term fluctuations, however, concentrate on the long-term investors are on the longterm fluctuations.

Morana and Beltratti (2008) investigated the stock markets movements of the U.S., the UK, Germany, and Japan. Their findings also supported an increasing co-movements 
between 1973 and 2004. Hanousek and Kocenda (2009) also studied Central and Eastern European stock markets. The findings of the study support the idea that Eastern European countries stock markets are strongly influenced by developed economies.

Madaleno and Pinho (2012) employed Coherence Morlet Wavelet to investigate international stock market indices co-movements. They used data from 4 indices: FTSE100, DJIA30, Nikkei225 and Bovespa. Their findings support that coherence among indices are high but not at the same level across scales. They also mention that local events affect that market quickly, but there is a significant time delay for the impact on other market indices. Moreover, they also draw attention to the high correlation in markets which are geographically and economically closer.

Czech stock market and the STOXX50 index has been analysed by Gjika and Horváth (2013). The correlations between markets observed to be higher during the recent financial crisis. Shahzad et al. (2016) support the idea that co-movement of the markets during the global financial crises shows a sudden increase, especially in the short term. Their results for the long run dependence illustrate that European stock markets have higher interdependence with Greece stock market.

In the literature, stock market co-movements are examined many times with various methods. The contagion effect or interconnection between markets have been increasing according to some studies, whereas some writers cannot reach the same results.

\section{Methodology - wavelet coherence}

\subsection{Wavelet}

This study has employed a bivariate framework called wavelet coherence. Wavelet Coherence is a very advantageous technique when the co-movement between twotime series is studied. In this research, continuous wavelet analysis tools are used, mainly wavelet coherence, to measure the degree of local correlation between time series in the time-frequency domain and wavelet coherence phase differences. To provide a better explanation for the wavelet coherence analysis, wavelet a real-valued square integrable function, $\psi \epsilon L^{2}(R)^{1}$, is defined as;

$$
\psi u j(t)=\frac{1}{\sqrt{j}} \psi \frac{t-u}{j} .
$$

$\frac{1}{\sqrt{j}}$ in this equation implies a normalization factor providing a unit variance of the wavelet $\left(\|\psi\|^{2}=1\right) . u$ and $j$ are the control parameters in the equations, where $u$ is a location parameter and $j$ is a scale parameter. Defining how the wavelet is stretched, scale has an inversed relation to frequency. Therefore, lower scale causes a more compressed wavelet, that can be seen as higher frequencies of a time series. The admissibility condition needs to be satisfied. The admissibility condition ensures reconstruction of a time series from its wavelet transform.

$$
C_{\psi}=\int_{0}^{\infty} \frac{|\psi(f)|^{2}}{f} d f<\infty .
$$

The condition in the second equation implies that the wavelet does not have a zero frequency component and so the wavelet has zero mean.

\subsection{The continuous wavelet transform}

$W x(u, j)$ can be obtained with the projection of a specific wavelet $\psi\left(\right.$.) onto the examined time series $x(t) \in L^{2}(R)^{1}$, i.e.,

$$
W x(u, j)=\int_{-\infty}^{\infty} x(t) \frac{1}{\sqrt{s}} \psi\left(\frac{\overline{t-u}}{j}\right) d t .
$$

It is eminent that the continuous wavelet transform has the ability to decompose and then subsequently perfectly reconstruct a time series

$$
x(t)=\frac{1}{C_{\psi}} \int_{0}^{\infty}\left[\int_{-\infty}^{\infty} W x(u, j) \psi_{u, j}(t) d u\right] \frac{d j}{j^{2}} .
$$

Moreover, this transform measures the size of the local correlation between time series

$\|x\|^{2}=\frac{1}{C_{\psi}} \int_{0}^{\infty}\left[\int_{-\infty}^{\infty}|W x(u, j)| d u\right] \frac{d j}{j^{2}}$.

\subsection{The Wavelet Coherence}

Definition of the cross wavelet power of two-time series $x(t)$ and $y(t)$ is as follows:

$$
W x y(u, j)=W x(u, j) \cdot W y *(u, j) .
$$

In Eq. (6), $W x(u, s)$ and $W y(u, s)$ represent continuous wavelet transforms of time series $x(t)$ and $y(t)$. The star (*) signifies a complex conjugate, parameter $u$ allocates a time position, and parameter $j$ symbolizes the scale parameter. A low wavelet scale denotes the high-frequency part of the time series - a short investment horizon (Torrence and Webster, 1999).

Whenever the time series exhibit a high common power, the cross wavelet power reveals areas in the time-frequency space. In the co-movement analysis, we search for areas where the two-time series in the time-frequency space 
co-movement, but do not necessarily have high power. A useful wavelet technique for finding these co-movements is wavelet coherence.

Torrence and Webster (1999) defines the squared wavelet coherence coefficient as

$$
R^{2}(u, j)=\frac{\left|S\left[j^{-1} W x y(u, j)\right)\right|^{2}}{S\left[\left[j^{-1}(W x(u, j))^{2}\right]\right] S\left[j^{-1}|W y(u, j)|^{2}\right]} .
$$

In Eq. (7), $S$ represents a smoothing operator. The coefficient $R^{2}(u, j)$ lies in the interval $[0,1]$. When there is a low correlation the $R^{2}$ becomes closer to zero, whereas stronger correlation is shown with the values closer to one. Therefore, $R^{2}$ explains the local linear correlation between two stationary time series at each scale and is analogous to the squared correlation coefficient in linear regression. Following formula is showing the phase differences according to Torrence and Webster (1999) definition:

$$
\theta_{x y}(u, j)=\tan ^{-1}\left(\frac{\mathcal{F}\left\{S\left(j^{-1} W_{x y}(u, j)\right)\right\}}{\mathfrak{R}\left\{S\left(j^{-1} W_{x y}(u, j)\right)\right\}}\right) .
$$

$\mathcal{F}$ is an imaginary and $\mathfrak{R}$ is a real part operator in this formulation. Black arrows in the wavelet coherence figures with significant coherence display the Phase differences. Once the two analysed time series move together on a particular scale, the arrows direct to the right showing the positive correlation. On the other hand, if the correlation is negative between time series then the arrows leads to the left. Then the arrows point to the left.

\section{Data and statistical issues}

This study investigates the financial contagion because of it may harm the global economy about portfolio risk management, the formulation of monetary and fiscal policy, and strategic asset allocation and pricing. This paper aims to show if there is a certain sign for a co-movement between markets during and after Greek Debt Crisis. To analyse the contagion during and after Greek Debt Crisis, the co-movements of six stock exchange markets has been examined for an eight-year term. Daily closing prices measured in domestic currencies of stock market indices, ASE, BIST100, WIG, FTSE100, DAX and BUX are used in this analysis between 06 March 2009 and 28 February 2017. Stock price data is provided by Bloomberg.

For the consistency of the data some exclusions have ben implied. Differences caused by the different trading days and holidays in countries resulted that some days have to be excluded. However, 1981 days' data were suitable for this analysis. This paper used EUR values of the stock exchange markets to avoid the imbalances occurred by depreciation or appreciation of the currencies during the term in the nonEuro zone. Description of the data is conducted by the following tables employing statistics analysis.

Descriptive statistics of the data enable us to see the high volatility during the studied term. Because of the differences in the index values of the markets, the comparison of the standard deviation and min-max values of the data is not meaningful. Therefore, it is convenient to check the coefficient of variation (CV), which is known as the relative standard deviation (RSD). In Table 1 the highest Standart Deviation / Mean ratio belongs to Greece by a large margin. It is approximately $61.7 \%$, whereas the other markets have this ratio around $20 \%$ or even less. This is a good illustration to show big fluctuations which have occurred in the 8-year period.

Table 2 shows us the correlation of the stock exchange market. As we can see DAX and FTSE100 indices are highly correlated. WIG is also highly correlated with FTSE and therefore with DAX. The correlation between Athens Stock Exchange and other markets are negative except Budapest Stock Exchange. This table gives us hints about the relations among the markets. But it doesn't enable us to observe if there is an increase in the correlation.

Table 1 Descriptive statistics

\begin{tabular}{lccccccc}
\hline & Mean & Med & Std dev. & Ske & Kurt & Min & Max \\
\hline ASE & $1,325.4$ & $1,047.2$ & 817.8 & 1.6 & 2.3 & 440.9 & $4,276.6$ \\
BUX & 70.5 & 67.3 & 14.9 & 0.1 & $(0.3)$ & 30.4 & 111.6 \\
FTSE 100 & $7,187.8$ & $7,274.0$ & $1,201.9$ & $(0.3)$ & $(0.1)$ & $3,872.3$ & $9,929.4$ \\
WSE WIG & $10,843.1$ & $11,123.9$ & $1,900.0$ & $(1.0)$ & 1.0 & $4,336.6$ & $14,300.2$ \\
XU100 BIST & $25,236.2$ & $25,600.2$ & $5,528.2$ & $(0.4)$ & 0.3 & $9,899.6$ & $39,279.0$ \\
DAX & $7,819.5$ & $7,291.2$ & $2,088.4$ & 0.2 & $(1.1)$ & $3,666.4$ & $12,231.3$ \\
\hline
\end{tabular}

Authors own 
Table 2 Correlation Matrix

\begin{tabular}{lccccc}
\hline & ASE & BUX & FTSE100 & WSEWIG & XU100BíST \\
\hline ASE & 1 & & & & \\
BUX & 0.1618 & 1 & & & \\
FTSE 100 & -0.4473 & 0.24 & 1 & & \\
WSE WIG & -0.0352 & 0.484 & 0.8074 & 1 & \\
XU100 BIST & -0.3196 & 0.1974 & 0.4615 & 0.5548 & 1 \\
DAX & -0.5383 & 0.2829 & 0.9348 & 0.6811 & 0.2964 \\
\hline
\end{tabular}

Author's own

\section{Results and discussion}

Following figures are showing the wavelet coherence between stock market indices of three countries. Arrows indicate the phase difference, and it enables us to understand the details about delays of oscillation of the two examined time series. In figures, arrows have different meanings. Primarily, it shows that there is a correlation between time series. But to understand the relation more in detail, direction of the arrow should be observed. For the positive correlation between series, Matlab uses the arrows point to the right. On the other hand, arrows directed to the left when there is a negative correlation and time series are anti-phase. And finally, when the arrows are pointing up means that the first time series leads the second one, an arrow pointing down indicates that the second time series leads the first one.

The figures are arranged as to show the data regarding periods rather than frequency because it is more suitable for our research. 0.75 Magnitude Squared Coherence is used for the analysis. Wavelet coherence values close to one indicate high correlation (denoted by warm colour in the figures), while values close to zero (white colour in the figures) indicate low or no correlation. The areas where the wavelet coherence is significant are bordered with a dashed white contour. The squared wavelet coherence coefficient can be regarded as a local linear correlation measure between two- time series in the time-frequency space.

In this analysis, due to the limitations of the same working days in the markets, every year has approximately 250 observations. Therefore, "500 days" period in the graph indicates two-years period. As observed from the graphs, ASE and other stock exchange markets coherence under the condition of 0.75 Magnitude Squared seemed to be weak. This magnitude level is relatively very high and ignores the weak correlations. For this reason, warm colours in the graphs are very limited, especially after a two-years period.
In 2009 and 2010, coherence is relatively high, and there is a positive correlation between ASE and all markets because the arrows are towards the right. But there is no dominant leading effect of any series. However, although there is a coherence especially in the first year, later coherence disappears.

There is a high coherence during 2012 (see the coherence around 1000th day in the Graph set). ASE has coherence BUX, DAX and WIG on this period again. But as the observations suggest, the coherence is diminishing especially after the first hit of the Mortgage crisis in Europe starting from 2009 till the end of 2010. Especially, the correlation of Eastern European stock markets and ASE has showed a decrease after 2012, when the government bond spreads reached the peak point. It is also surprising that FTSE100 and BIST100 have very weak correlation with the Athens Stock Exchange Market data.

\section{Conclusion}

For this study between six countries' time series, bivariate wavelet technique called wavelet coherence is employed. The area under the white arc of the Wavelet Coherence graphics shows the significant movements. While warmer colours imply higher coherence, blue is showing no correlation. The arrows show the lag between indices.

This study supports the previous literature by using a different mean of calculation. As wavelet coherence tool results at Fig. 4 show that at the beginning of 2009 and during 2012, coherence is high between the markets, whereas when the severity of crises slowed down coherence is diminished. This analysis contributes the literature by observing the leverage effect, similar to the findings of Baruník and Vácha (2013), Gjika and Horváth (2013) and many others. This study supports the idea that during crises period, diversification is low in European markets, because of the increase in the interconnection of markets during this period.

Also in the last year period, there is a visible high coherence between FTSE and ASE. This high positive 

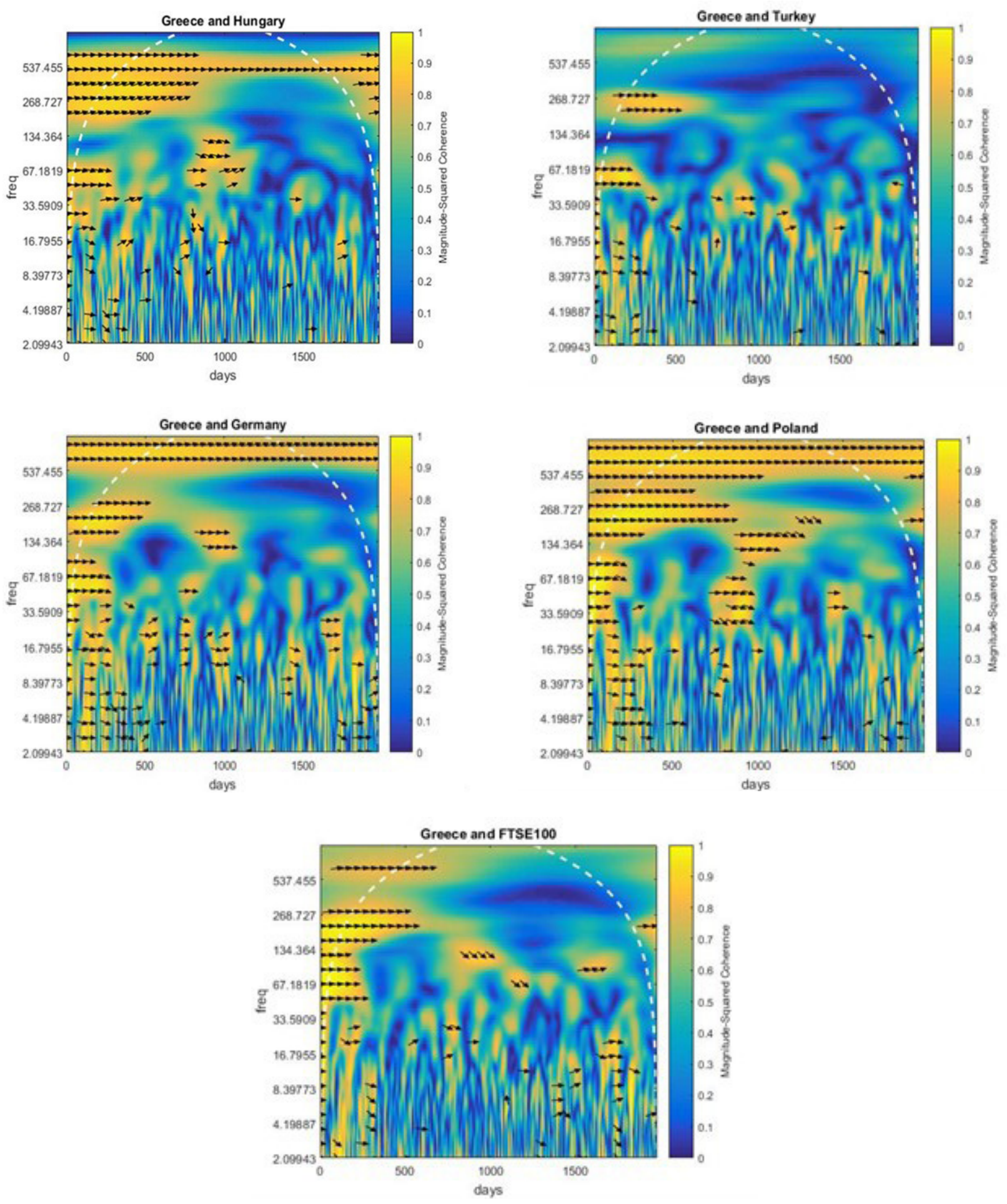

Fig. 4 Set of Wavelet Coherence

correlation appeared after mid-2016 when the UK voted for Brexit, which also caused sanctions in the stock markets. Istanbul Stock Exchange market showed no coherence at almost any time. This is a sign of high interconnection of the markets within the EU. As a non-member of the union Turkish Stock Exchange did not show co-movements.
This research by employing the wavelet theory has aimed to explain the leverage effect among stock exchange markets during Greek debt crisis. The wavelet method has been used in many fields to illustrate the coherence between two elements. However, using wavelet theory to explain the co-movements of time series with financial data is 
relatively new. Especially the explanation of the leverage effect between low and high volatility period is introduced in the literature with this analysis.

All in all, the results of this study exhibits that during crisis an increased integration in the financial markets actually rises the risk spread from other countries. And also positive signs in an economy do not affect other economies as well as negative movements. Therefore, the gains from integration have been observed to be less than

\section{References}

Banz, R. W. (1981) "The relationship between return and market value of common stocks", Journal of Financial Economics, 9(1), pp. 3-18. https://doi.org/10.1016/0304-405X(81)90018-0

Baruník, J., Vácha, L. (2013) "Contagion among Central and Eastern European Stock Markets during the Financial Crisis", Czech Journal of Economics and Finance, 63(5), pp. 443-453.

Beck, T., Levine R. (2004) "Stock markets, banks, and growth: Panel evidence", Journal of Banking \& Finance, 28(3), pp. 423-442. https://doi.org/10.1016/s0378-4266(02)00408-9

Beirne, J., Fratzscher, M. (2013) "The pricing of sovereign risk and contagion during the European sovereign debt crisis", Journal of International Money and Finance, 34, pp. 60-82. https://doi.org/10.1016/j.jimonfin.2012.11.004

Belkin, P., Mix, D. E., Nelson, R. M. (2011) "Greece's Debt Crisis: Overview, Policy Responses, and Implications", Library of Congress, Congressional Research Service, Washington, USA, CRS Report for Congress, R41167.

Bloomberg (n.d.) "Stock price graph for Apple Inc. January 1, 2008 March 1st, 2017, via Bloomberg LP" Available at: https:/www. bloomberg.com/markets/rates-bonds [Accessed: 12 March 2017]

Candelon, B., Piplack, J., Straetmans, S. (2008) "On measuring synchronization of bulls and bears: The case of East Asia", Journal of Banking \& Finance, 32(6), pp. 1022-1035. https://doi.org/10.1016/j.jbankfin.2007.08.003

Chordia, T., Sarkar, A., Subrahmanyam, A. (2005) "An Empirical Analysis of Stock and Bond Market Liquidity", The Review of Financial Studies, 18(1), pp. 85-129. https://oi.org/10.1093/rfs/hhi010

Connolly, R. A., Stivers, C., Sun, L. (2007) "Commonality in the time-variation of stock-stock and stock-bond return comovements", Journal of Financial Markets, 10(2), pp. 192-218. https://doi.org/10.1016/j.finmar.2006.09.005

De Santis, R. A. (2012) "The Euro area sovereign debt crisis: safe haven, credit rating agencies and the spread of the fever from Greece, Ireland and Portugal", No 1419, Working Paper Series, European Central Bank.

Égert, B., Kočenda, E. (2007) "Interdependence between Eastern and Western European stock markets: Evidence from intraday data", Economic Systems, 31(2), pp. 184-203. https://doi.org/10.1016/j.ecosys.2006.12.004 the downturns. This can be called as a leverage effect which means the negative movement in volatility is stronger than the positive one. These results are valid only for the observed period and observed variables in studied stock exchange markets.

For further analysis, different time periods and events may be selected to improve the results. As the technique is very useful to analyze the time series, it can be very useful to use wavelet to explain various literature gap in finance.

Featherstone, K. (2011) "The JCMS Annual Lecture: The Greek Ssovereign Debt Crisis and EMU: A Failing State in a Skewed Regime", JCMS: Journal of Common Market Studies, 49(2), pp. 193-217.

https://doi.org/10.1111/j.1468-5965.2010.02139.x

Gilmore, C. G., Lucey, B. M., McManus, G. M. (2008) "The dynamics of Central European equity market comovements", The Quarterly Review of Economics and Finance, 48(3), pp. 605-622. https://doi.org/10.1016/j.qref.2006.06.005

Gjika, D., Horváth, R. (2013) "Stock market comovements in Central Europe: Evidence from the asymmetric DCC model", Economic Modelling, 33, pp. 55-64. https://doi.org/10.1016/j.econmod.2013.03.015

Grieco, J. M. (1997) "Systemic sources of variation in regional institutionalization in Western Europe, East Asia, and the Americas", In: The Political Economy of Regionalism, Columbia University Press, New York, USA, pp. 164-187.

Hanousek, J., Kocenda, E. (2009) "Intraday Price Discovery in Emerging European Stock Markets", CERGE-EI Working Paper No. 382. https://doi.org/10.2139/ssrn.1448618

Huang, B.-N., Hwang, M. J., Yang, C. W. (2008) "Causal relationship between energy consumption and GDP growth revisited: a dynamic panel data approach", Ecological Economics, 67(1), pp. 41-54. https://doi.org/10.1016/j.ecolecon.2007.11.006

Hull, J., Predescu, M., White, A. (2004) "The relationship between credit default swap spreads, bond yields, and credit rating announcements", Journal of Banking \& Finance, 28(11), pp. 2789-2811. https://doi.org/10.1016/j.jbankfin.2004.06.010

Humpe, A., Mcmillian, P. (2009) "Can macroeconomic variables explain long-term stock market movements? A comparison of the US and Japan", Applied Financial Economics, 19(2), pp. 111-119. https://doi.org/10.1080/09603100701748956

Katzenstein, P. J. (2005) "World of Regions: Asia and Europe in the American imperium", Cornell University Press, Ithaca, NY, USA. https://doi.org/10.7591/9781501700385

Kentikelenis, A., Karanikolos, M., Papanicolas, I., Basu, S., McKee, M., Stuckler, D. (2011) "Health effects of financial crisis: omens of a Greek tragedy", The Lancet, 378(9801), pp. 1457-1458. https://doi.org/10.1016/s0140-6736(11)61556-0 
Kouretas, G. P., Prodromos, V. (2010) "The Greek crisis: Causes and implications", Panoeconomicus, 57(4), pp. 391-404. https://doi.org/10.2298/pan1004391k

Madaleno, M., Pinho, C. (2012) "International stock market indices comovements: a new look", International Journal of Finance \& Economics, 17(1), pp. 89-102. https://doi.org/10.1002/ijfe.448

Martin, P. (1998) "Can Regional Policies Affect Growth and Geography in Europe?", The World Economy, 21(6), pp. 757-774. https://doi.org/10.1111/1467-9701.00162

Morana, C., Beltratti, A. (2008) "Comovements in international stock markets", International Financial Markets, Institutions and Money, 18(1), pp. 31-45. https://doi.org/10.1016/j.intfin.2006.05.001

Shahzad, S. J. H., Kumar, R., Ali, S., Ameer, S. (2016) "Interdependence between Greece and other European stock markets: A comparison of wavelet and VMD copula, and the portfolio implications", Physica A: Statistical Mechanics and its Applications, 457, pp. 8-33. https://doi.org/10.1016/j.physa.2016.03.048
Stock, J. H., Watson, M. W. (1989) "New Indexes of Coincident and Leading Economic Indicators", NBER Macroeconomics Annual, 4, pp. 351-394.

https://doi.org/10.2307/3584985

The World Bank (n.d.) "World Bank Open Data: Free and open access to global development data" [online] Available at: http://data.worldbank.org/ [Accessed: 15 March 2017]

Torrence, C., Webster, P. J. (1999) "Interdecadal Changes in the ENSOMonsoon System", Journal of Climate, 12(8), pp. 2679-2690.

https://doi.org/10.1175/1520-0442(1999)012<267 9:ICITEM $>2.0 . \mathrm{CO} ; 2$

Vassalou, M. (2003) "News related to future GDP growth as a risk factor in equity returns", Journal of Financial Economics, 68(1), pp. 47-73.

https://doi.org/10.1016/s0304-405x(02)00248-9 